\title{
A Microcosmic Research of Library Layering Service Equity
}

\author{
Zhiyuan Zhao \\ Library of Baicheng Normal University, Jilin Province, China
}

ZhiyuanZhao@163.com

\section{Keywords:Library; Layering service; Equity; Microcosmic; Exploration}

\begin{abstract}
As infrastructure of Chinese cultural construction, library is of far-reaching importance to the promotion of comprehensive national quality. Implementing layering service in libraries is effective utilization of library resources. Layering services at demands of different groups represents equity of library service microscopically. Implementing layering service in libraries conforms to the basic spirit of humanistic care and is of promotion role to the service quality of librarians. This paper starts from social functions represented by the current society and analyzes the layering service of libraries, trying to explore microcosmic equity of library layering service.

With the continuous development of Chinese social economy, construction of Chinese libraries also ushers in great reforms. Because of the acceleration of pace of city life, people's life becomes increasingly abundant. People need to improve their cultural qualities and accomplishment, but it is hard to find a quite public place to study. Therefore, library becomes the right place for people to study, get rid of pressure and enrich their spirit world. Increasingly more people choose to study in libraries, which creates more and more types of service objects to libraries. Therefore, it is hard to guarantee service quality with united service mode and layering service becomes an effective measure for libraries to deepen reform and innovation.
\end{abstract}

\section{Social functions of Chinese libraries}

Functions of libraries receive gradual completion during a long development process and they develop from simple to complicated, from low-level to advanced with the development of society. Since human civilization has advanced rapidly in the current age, especially today when we are embracing the new age of reform and opening up, when people's material life gets promoted greatly, their pursuit of spiritual life is much stronger. People hope to enhance their cultural standards and qualities with scientific and cultural knowledge. In order to satisfy people's cultural and spiritual pursuit and learn more knowledge, library is exerting its strong social cultural functions with its equity and openness.

When the society has not realized informatization, library is the major route for people to study and look for document literatures. At present, when informatization is developing rapidly, though people generally use computers to search for problems they need to solve, they cannot find enough materials because of permission settings sometimes. At this time, most people would choose libraries for consultation of relative materials. Wide application of smartphones and e-books have become the most prevailing way of reading, which not only saves a large amount of money, but also allows people to read anytime anywhere and makes people's life convenient. However, e-books cannot replace the sense of reality that paper books give to people. According to a recent survey, paper books have high popularity at present and their purchase quantity has increased compared with the corresponding period. However, purchasing all the needed books would cause certain economic burdens to people. Therefore, people who want to read paper books would turn their eyes to libraries, which can not only provide a quite reading environment, but also comfortable reading atmosphere. Today, when people are pursuing cost performance, library is also an important representation of high cost performance.

Libraries can hold various lectures regularly, enrich people's spare-time life and improve people's spiritual shackles. Libraries in cities represent the cultural deposits and intensions of the cities. No matter it is traditional library or the current intellectualized library, they are all of far-reaching importance to the promotion of Chinese comprehensive quality. 


\section{Service intension of library layering service}

With more and more people choose to read and study in libraries, service objects of libraries include children, middle school students, senior citizens and people working in differed fields. Because of different living environment and learning experiences, different readers have different demands for library services, which makes service objects of libraries various. If united service requirements are still in use, it would reduce a part of readers' satisfaction of library services.

Adopting layering service inside libraries is to admit differences of readers. Layering service means starting from readers' perspective and classifying service types from low to high according to readers' age and reading habits and so on, and readers can choose service layers according to themselves. Modes of layering service can also adjust libraries' service content and service layers according to service quality in time. Service mode of library layering service can make various hardware and software facilities in libraries be utilized reasonably and improve resource utilization inside the library. Librarians can find service objects that suit them during the process of layering service and improve service quality of the library efficiently. Because of the rapid development of science, limitless information resources strike people's eyes desultorily and force libraries to conduct a comprehensive reform and realize innovative layering service in service mode.

Library layering service has the following characteristics: firstly, it represents readers' subjectivity. Adopting this service mode indicates that libraries start from readers' perspective, considers for readers, provides good-quality service for readers and puts readers at the priority of services. Secondly, it represents librarians' guidance. During service process, they offer help to readers according to readers' demands and service content, showing librarians' guidance. Thirdly, it represents libraries' integral development. During the services process, it should both implement service according to readers' characteristics and understand readers' integral conditions. It should consider both parties timely and represent integrality of library service.

\section{Analyzing equity of library layering service from microcosmic perspective}

Many people propose doubts to library layering service, holding that this is discrimination or different treatment to service objects. In fact, the purpose that libraries carry out layering service is to satisfy different service objects' individual requirements so that services of libraries can reach equity at microcosmic layer.

Equity in library layering service. A lot of people believe that library layering service violates requirements of library service equity and it is special discrimination and different treatment to readers. What the public should pay attention to is that layering service of libraries is not dividing people according to their social status or economic conditions; rather, it means dividing readers from their own perspectives. Libraries divide readers according to their reading habits, requirements to services, personalities, logical thinking and so on. This layering means admitting readers' personalities and respecting readers so that readers can have high-quality services and it is layering that guarantees service quality of libraries. The layering not only includes service objects, but also service quality of librarians. Librarians adopt different service mode according to different service objects, which is respecting readers' personality characteristics.

Currently, Chinese economy is increasing smoothly and steadily. Different readers accept current social changes in different degrees, which leads to changes of readers' gaps. Libraries' layer standards are also adjusted continuously with social changes. Differences among readers determine differences of the height that could be achieved. Library layering is also the product of social development. Implementing the same service to different kinds of readers is just like communal pot during People's Commune Period, which seems to be fair;. However, if analyzed microscopically, you will find that different readers have different adaptability to the same service. When receiving the same services, readers with poor adaptability would feel pressure and it would give rise to conflicts between readers and librarians, which is inequity to readers. Layering of readers means looking at library services with development perspective and implementing equity in microcosmic areas. 
Equity in readers' requirements. Dividing resources and personnel inside libraries according to readers' requirements and realizing equity of layering service. At present, many parents choose to take their children to libraries for study and reading and libraries would consider the reading requirements of this part of young children. They can open a children's reading zone with fairy tales, science and cartoons as major reading books. The environment setting should also be different from adults' reading zone. Because of their young age and active personalities, children should be provided with relaxed reading atmosphere. Therefore, colorful pictures should be used in large quantities so as to create reading atmosphere for children. Parents can rest assure that children can carry out activities in this reading zone and they can read with relief, which provides convenience to parents.

Many readers do not have timely understanding of newly published books and periodicals, which shrinks their reading scope and they feel that the library's reserve is not big enough. For the sake that resources in libraries get utilized timely and reasonably, libraries would recommend the new books or periodicals at regular intervals, and they will divide the newly-brought reserve according to readers' requirements so that readers can choose layering service with librarians more conveniently.

Libraries should carry out communication activities at regular intervals and have readers at the same layers evaluate services in this period; also, readers can point out disadvantages in the service process so that librarians can improve them, adjust standards of layering service and establish humane service philosophy. Readers at the same layer can exchange their ideas about the books they have read during this time by means of the communication activities, during which process readers can show their self-value.

Equity in service layering. Differences of personalities lead to differences of readers. After learning differences of readers, librarians should conduct differentiated service to different types of readers. This differentiated service should not just stay at the tip of tongue; rather, they should be represented in service content. Librarians should not adopt service content of "sweeping approach" to different layers of readers. Readers at the same layer have similar service requirement, so representing readers' differences during service means starting from readers' perspective and providing convenient service environment and services to readers. Understanding readers' gap correctly does not mean librarians would serve readers with tainted spectacles; rather, it means providing excellent services to readers with different requirements. Service content layering is the premise and safeguard for providing high-quality services to readers.

\section{Relative measures of realizing library layering service equity at microcosmic layer}

To realize library layering service equity at microcosmic layer, the following several aspects should be used at entry point.

Firstly, qualities of librarians should be improved efficiently and timely. Professional qualities of librarians are the guarantee of service quality. Differences of service layers have different demands for librarians' abilities, which does not necessarily mean that librarians with low abilities should service at low layers; rather, it means combining librarians' qualities and allocating service content reasonably for the convenience of services. During the service process, librarians should improve their own qualities, which can drive the promotion of service qualities.

Secondly, readers' requirements should be organized. Libraries should have timely understanding of readers' requirements. However, when readers propose demands, libraries should have appropriate guidance to readers so that readers can propose reasonable requirements for the improvement of libraries. Librarians organize readers' requirements so that readers can become inner clues of layering service. Libraries should try their uttermost to satisfy readers' reasonable requirements and encourage readers to propose improvement strategies to libraries and promote favorable development of libraries.

Thirdly, libraries should adjust layering service standards in time. Layering standards of libraries are not changeless; rather, they are adjusted dynamically with readers' requirements. With the increase of reading, readers' intension is also increased continuously and readers' qualities are 
rising incessantly. Serving the improving readers with original service content cannot represent the essence of layering service. Libraries should hold reading meetings at regular intervals. During the meeting, librarians can grasp the changes of readers' intension and adjust their service content in time.

\section{Conclusion}

At present, a key problem that library faces is how to satisfy requirements of different kinds of people under the premise of service equity. Therefore, library layering service catches the attention of librarians. When libraries implement layering service, it means efficient utilization of various resources inside the library. Layering service makes service content and service objects pertinent obviously and is convenient for libraries to implement good services. Layering service is microcosmic representation of library equity and makes service quality of libraries promote to a new stage.

\section{References}

[1] Liu Xueping, Cai Lanrong. Microcosmic Exploration of Library Layering Service Equity. Library Work and Study,2015 (04)

[2] Wang Lunsheng, Song Chuanling. On Reader Service of University Library from Demand Layering Theory. Lantai World, 2014 (14)

[3] Liu Xueping. Microcosmic Realization of University Library Socialization Layering Service Equity based on Readers’ Demands. Library ,2014（04）.

[4] Cheng Zhen. On National Library Layering Service. National Library Journal,2006（01.

[5]Li Gaofeng. Research and Construction of Library Service Equity Evaluation . Library,2013 (04.

[6] Chu Cunkun, Sun Siqin. A Research of University Library Discipline Librarian Layering Service Model. Library Work and Study,2012 (02) 